[Agr. Biol. Chem., Vol. 32, No. 10, p. 1239 1245, 1968]

\title{
Gibberellins in Immature Seeds of Pharbitis nil
}

\author{
Part I. Isolation and Structure of a Novel Gibberellin, \\ Gibberellin $\mathrm{A}_{20}$
}

\author{
By Noboru Murofushi, Nobutaka Takahashi, Takao Yokota \\ and Saburo TAmURA \\ Department of Agricultural Chemistry, The University of Tokyo, Bunkyo-ku, Tokyo \\ Received April 24, 1968
}

\begin{abstract}
A new gibberellin, gibberellin $A_{20}\left(G_{20}\right)$, was isolated from immature seeds of morning-glory (Pharbitis nil). Its structure was established as $4 a \alpha, 7 \alpha$-dihydroxy-1 $\beta$-methyl8-methylenegibbane-1 $\alpha, 10 \beta$-dicarboxylic acid-1 $\rightarrow 4$ a lactone (I) on the basis of its physicochemical analysis as well as chemical evidences. $\mathbf{G A}_{20}$ shows marked growth promoting activities on dwarf maize $d_{2}$ and $d_{5}$ but weak activities on $d_{1}$, rice seedling and dwarf pea.
\end{abstract}

The presence of gibberellin-like substances in immature seeds of morning-glory (Pharbitis nil) has been suggested by Ogawa, ${ }^{1,2)}$ Mura$\mathrm{kami}^{3}{ }^{3}$ and Zeevaart. ${ }^{4)}$ In the preliminary reports, ${ }^{5,6)}$ we have presented the isolation of a novel gibberellin, gibberellin $\mathrm{A}_{20}\left(\mathrm{GA}_{20}\right)(\mathrm{I})$, from the same seeds together with the assignment of its structure. Here we wish to report the details of the isolation procedure, structural assignment and biological activities of $\mathrm{GA}_{20}$ as well as the co-existence of $\mathrm{GA}_{3}$ and $\mathrm{GA}_{5}$.

The immature seeds $(60 \mathrm{~kg})$ were extracted with methanol using a blender and the extract was concentrated in vacuo. The aqueous residue was extracted with ethyl acetate and $n$-butanol successively. Each fraction was separated into acidic and neutral fractions

1) Y. Ogawa, Plant and Cell Physiol., 4, 217 (1963).

2) Y. Ogawa, Bot. Mag. Tokyo, 79, 69 (1966).

3) Y. Murakami, ibid., 74, 241 (1961).

4) J. A. D. Zeevaart, Plant Physiol., 41, 856 (1966).

5) N. Takahashi, N. Murofushi, T. Yokota and S. Tamura, Tetrahedron Letters, 1967, 1065.

6) N. Takahashi, N. Murofushi, T. Yokota and S. Tamura, Presented at the VIth International Conference on Plant Growth Substances, Ottawa, Canada, 1967.

7) S. Tamura, N. Takahashi, T. Yokota, N. Murofushi and Y. Ogawa, Planta, 78, 208 (1968). by the usual method. As preliminarily reported, the butanol-soluble acidic fraction showed marked growth promoting activity to rice seedlings and was found to contain $\mathrm{GA}_{3}$ glucoside together with other two watersoluble gibberellins. ${ }^{6,71}$

The ethyl acetate-soluble acidic fraction was purified by method illustrated in Fig. 1. At first ten transfers countercurrent distribution was conducted. The active fractions were combined and chromatographed on a charcoal column. Elution with acetone-water mixtures gave active fractions F-I $(50: 50$ and $60: 40$, acetone-water, $v / v)$ and F-II $(70: 30$, $\mathrm{v} / \mathrm{v})$. The presence of different active principles in F-I and F-II was suggested by the histograms obtained from thin layer chromatography and bioassay. Each fraction was successively purified through silicic acid adsorption and preparative thin layer chromatography. Thus F-I showed a fluorescent spot under ultra-violet light at $\mathrm{R}_{\mathrm{GA}_{3}} 1.00$ on a thin layer chromatogram treated with $70 \%$ sulfuric acid without heating. The extract from this zone exhibited marked activity on dwarf maize $d_{5}$. The methylated sample obtained from the active zone on treatment with diazomethane revealed a fluorescent spot with 


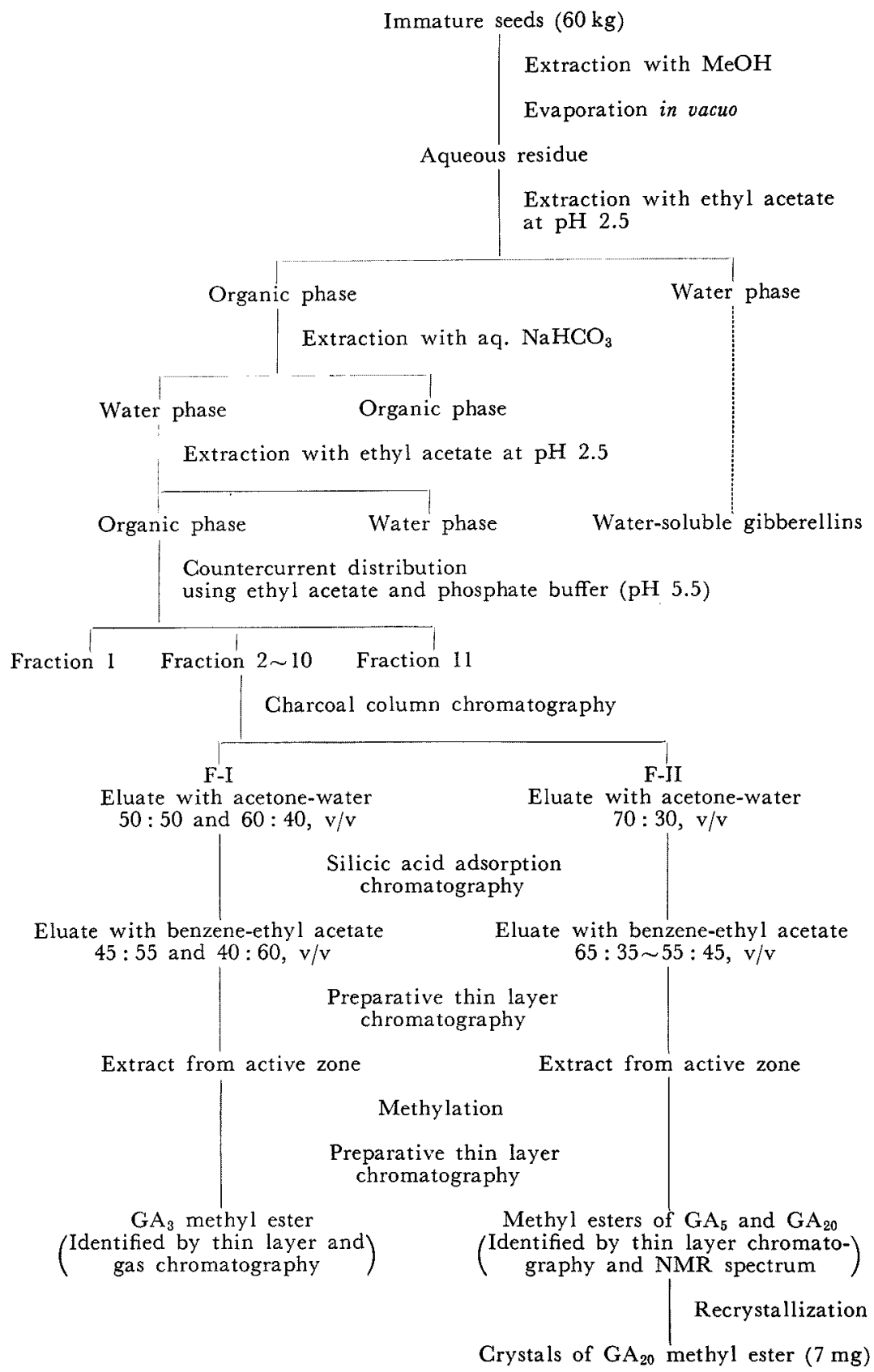

FIG. 1. Isolation Procedure for Gibberellins in Immature Seeds of Morning-glory. 
sulfuric acid on thin layer chromatography and an evident peak on gas chromatography, the $R f$ value and retention time being identical with those of $\mathrm{GA}_{3}$ methyl ester. Thus, the presence of $\mathrm{GA}_{3}$ in the seeds was established.

Purified F-II on a thin layer chromatogram showed a fluorescent spot at $\mathrm{R}_{\mathrm{GA}_{3}} 1.60$ on treatment with sulfuric acid followed by heating. This spot exhibited strong growth promoting activity on dwarf maize $d_{5}$ and rather weak activity on $d_{1}$ and rice seedling. Since the active principle could not be obtained as crystals by preparative thin layer chromatography, it was converted to the methyl ester, which showed a fluorescent spot at $\mathrm{R}_{\mathrm{GA}_{2}-\mathrm{Me}} 1.82$ on a thin layer plate with sulfuric acid. Preparative thin layer chromatography of the ester followed by recrystallization afforded $7 \mathrm{mg}$ of colorless crystals melting at $181^{\circ} \mathrm{C}$. Alkaline hydrolysis of the ester afforded an acid melting at $232 \sim 233^{\circ} \mathrm{C}$, which regenerated the original ester on treatment with diazomethane, indicating that simple hydrolysis occurred. The free acid and its methyl ester thus obtained revealed almost identical $R f$ values with those of $\mathrm{GA}_{5}$ and its methyl ester (III) on thin layer chromatograms, and the growth promoting activities of the acid on dwarf maize $d_{1}, d_{5}$ and rice seedlings resembled those of $\mathrm{GA}_{5}$. However, IR spectrum of the ester was different from not only III but also any known gib-

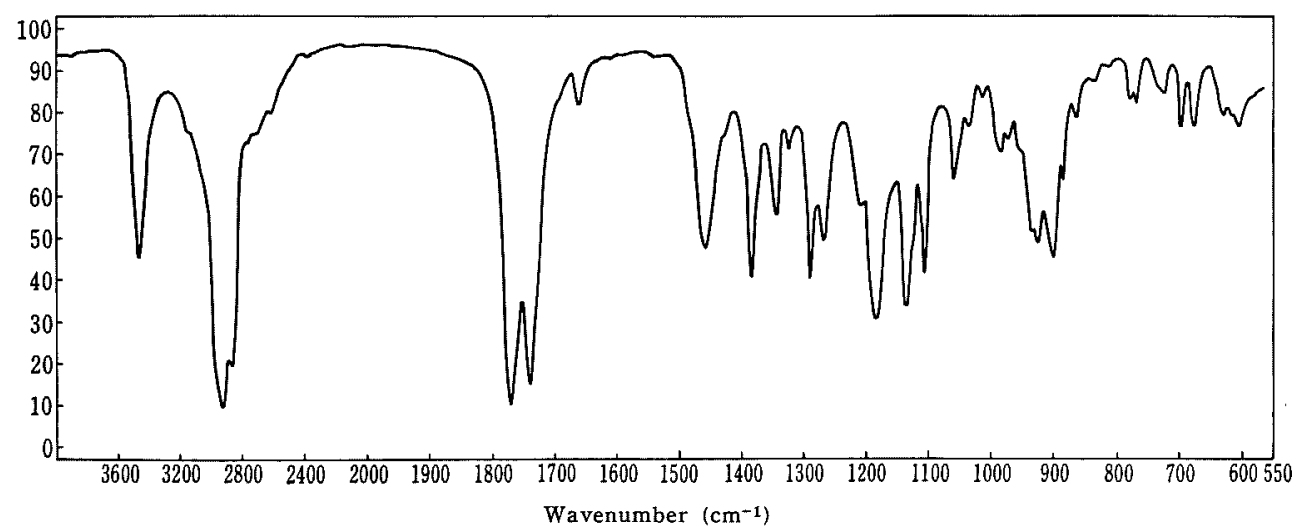

FIG. 2. IR Spectrum of Gibberellin $A_{20}$ (Nujol).

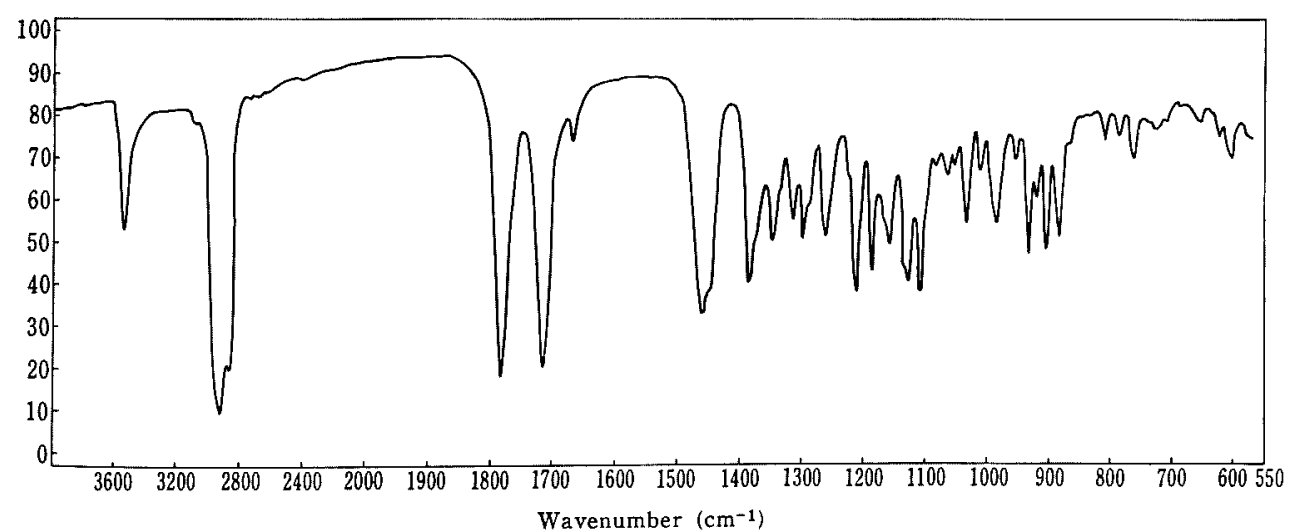

FIG. 3. IR Spectrum of Gibberellin $A_{20}$ Methyl Ester (Nujol). 


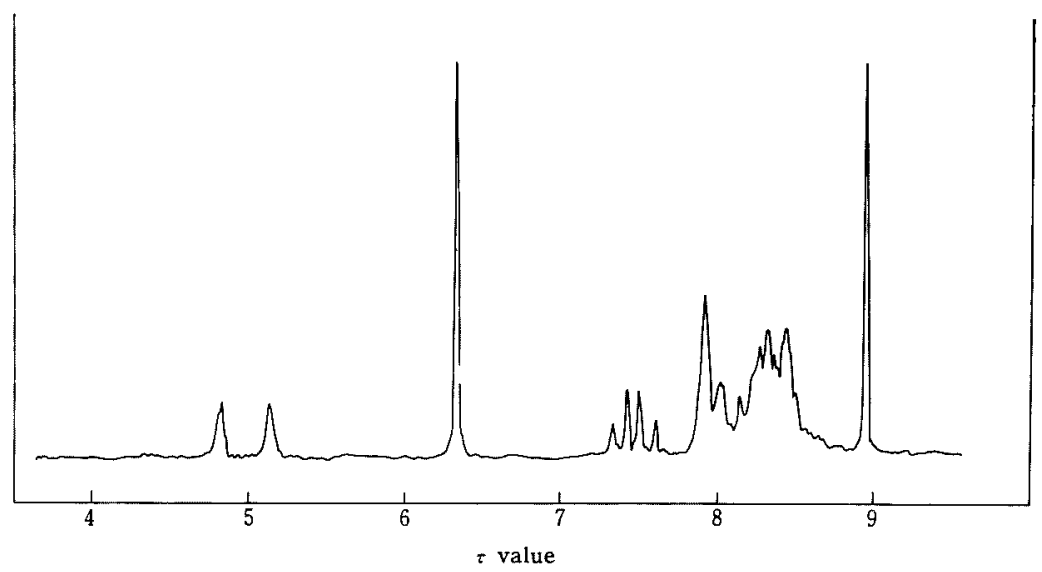

FIG. 4. NMR Spectrum of Gibberellin $\mathrm{A}_{20}$ Methyl Ester ( $\mathrm{CDGl}_{3}$ ).

berellin methyl esters. Thus the acid was decided to be a new gibberellin, and named pharbitis gibberellin, later, gibberellin $\mathrm{A}_{20}$ according to the proposal by MacMillan and Takahashi. ${ }^{81}$ IR spectra of $\mathrm{GA}_{20}$ and its methyl ester are shown in Fig. 2 and 3.

The occurrence of $\mathrm{GA}_{5}$ in the fraction containing $\mathrm{GA}_{20}$ was indicated by the presence of weak signals due to III in the NMR spectrum of crude $\mathrm{GA}_{20}$ methyl ester, which revealed a $3 \mathrm{H}$ singlet of $\mathrm{C}-1$ methyl at $\tau 8.78$, an $\mathrm{AB}$ quartet of $\mathrm{C}-10$ and $10 \mathrm{a}$ protons at $\tau 7.13$ and 7.40 and complicated signals of $\mathrm{C}-2$ and $\mathrm{C}-3$ olefinic protons at $\tau$ 4.1 4.5. The content of $\mathrm{GA}_{5}$ is estimated to be less than $10 \%$ of $\mathrm{GA}_{20}$ based on comparison of intensities of the signals corresponding to the both esters.

The high resolution mass spectrum of $\mathrm{GA}_{20}$ methyl ester revealed a parent ion peak at 346.177 with the composition of $\mathrm{C}_{20} \mathrm{H}_{26} \mathrm{O}_{5}$ (calculated value, 346.178). The NMR spectrum of the methyl ester in deuterochloroform showed a methoxyl signal at $\tau 6.33$, indicating $\mathrm{GA}_{20}$ to be monobasic. Therefore, the molecular formula $\mathrm{C}_{19} \mathrm{H}_{24} \mathrm{O}_{5}$ was assigned to $\mathrm{GA}_{20}$. The IR spectrum of the ester suggested the presence of functional groups illustrated

8) J. MacMillan and N. Takahashi, Nature, 217, 170 (1968). in Table I. In the high resolution mass spectrum, $\mathrm{GA}_{20}$ methyl ester exhibited prominent peaks due to $\mathrm{M}-32\left(\mathrm{CH}_{4} \mathrm{O}\right), \mathrm{M}-46\left(\mathrm{CH}_{2} \mathrm{O}_{2}\right)$, $\mathrm{M}-60\left(\mathrm{C}_{2} \mathrm{H}_{4} \mathrm{O}_{2}\right), \mathrm{M}-78\left(\mathrm{C}_{2} \mathrm{H}_{6} \mathrm{O}_{3}\right), \mathrm{M}-104\left(\mathrm{C}_{3} \mathrm{H}_{4} \mathrm{O}_{4}\right)$, $\mathrm{M}-106\left(\mathrm{C}_{3} \mathrm{H}_{6} \mathrm{O}_{4}\right)$ and $\mathrm{M}-122\left(\mathrm{C}_{3} \mathrm{H}_{6} \mathrm{O}_{5}\right)$ fragment ions which constitute a characteristic pattern of $\mathrm{C}_{19}$ gibberellin methyl esters. ${ }^{97}$ Appearance of $\mathrm{C}_{17}$ fragment ions as the largest hydrocarbon fragments suggests the presence of a gibbane ring (VI). This is further supported by the presence of the $A B$ quartet due to C-10 and C-10a protons at $\tau 7.50$ and 7.33 ( $J=10 \mathrm{cps}$ ), which has been known to be characteristic of a gibbane ring.

TABLE I. FUnCtional GRoups OF GA 20 METHYL ESTER

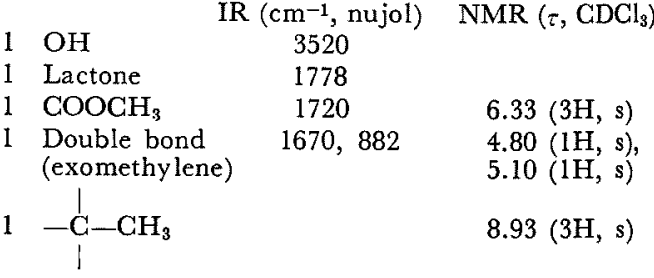

According to the Hanson's information, ${ }^{101}$ the NMR spectrum of $\mathrm{GA}_{20}$ methyl ester measured in deuterochloroform was compared

9) N. Takahashi, N. Murofushi, S. Tamura, N. Wasada, H. Hoshino, T. Tsuchiya, T. Aoyama and H. Morita, Tetrahedron Letters, 1967, 865. 
with that in pyridine in details. The C-1 methyl signal was observed at $\tau 8.93$ in deuterochloroform and $\tau 8.85$ in pyridine. This slight shift in pyridine suggests the absence of a hydroxyl group at C-2. This is concordant with the observation that an $\mathrm{AB}$ quartet due to $\mathrm{C}-10$ and $\mathrm{C}-10 \mathrm{a}$ protons at $\tau 7.50$ and $7.33(J=10 \mathrm{cps})$ in deuterochloroform does not shift downfield so much in pyridine. Two $1 \mathrm{H}$ singlets due to the $\mathrm{C}-8$ exomethylene exist at $\tau 5.10$ and 4.80 in deuterochloroform, and at $\tau 4.94$ and 4.42 in pyridine. This downfield shift of one of the exomethylene protons in pyridine can be explained by the presence of a hydroxyl group at C-7. These physicochemical evidences allow to assign the plane structure of II to $\mathrm{GA}_{20}$ methyl ester.

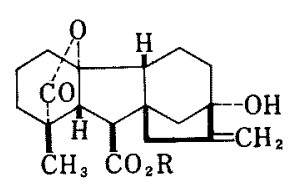

I $\mathrm{R}=\mathrm{H}$

II $\mathrm{R}=\mathrm{CH}_{3}$

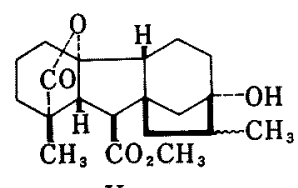

$\mathrm{V}$
III $\mathrm{R}=\mathrm{CH}_{2}$ IV $\mathrm{R}=\mathrm{H}, \mathrm{CH}_{3}$

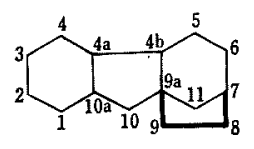

VI

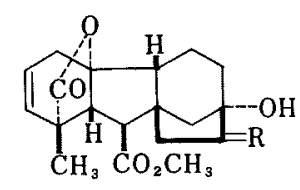

This conclusion was further confirmed through chemical conversion of III into II by partial hydrogenation. Cross et al. ${ }^{11}$ reported partial hydrogenation of $\mathrm{C}-3 \sim \mathrm{C}-4$ double bond in $\mathrm{GA}_{7}$ methyl ester to afford $\mathrm{GA}_{4}$ methyl ester by the use of the partially poisoned palladium-barium carbonate catalyst. Application of this procedure to III, however, did not give the anticipated single compound but mixture of equal amounts of II, III, IV and $V$. The mixture was successfully separated through adsorption chromatography by

10) J. R. Hanson, J. Chem. Soc., 1965, 5036.

11) B. E. Cross, R. H. B. Galt and J.R. Hanson, Tetrahedron, 18, 451 (1962).

the use of silicic acid impregnated with silver nitrate. II thus obtained was completely identical with the methyl ester of natural $\mathrm{GA}_{20}$ in all respects, IR, NMR and melting point. Thus, stereochemical formulas of $\mathrm{GA}_{20}$ and its methyl ester could be established as I and II, respectively.

TABLE II. GRowTh Promoting ACtivities of $\mathrm{GA}_{20}, \mathrm{GA}_{3}$ AND GA $\mathrm{A}_{5}$ ON HIgher PLANTS

A) Activities on dwarf maize mutants, $d_{1}, d_{2}$ and $d_{5}$

\begin{tabular}{|c|c|c|c|c|}
\hline \multirow{2}{*}{ Mutant } & \multirow{2}{*}{$\begin{array}{c}\text { Dosage } \\
(\mu \mathrm{g} / \text { plant })\end{array}$} & \multicolumn{3}{|c|}{$\begin{array}{l}\text { Sum of } 1 \text { st and } 2 \text { nd leaf- } \\
\text { sheath lengths (mm) }\end{array}$} \\
\hline & & $\mathrm{GA}_{3}$ & $\mathrm{GA}_{5}$ & $\mathrm{GA}_{20}$ \\
\hline$d_{1}$ & $\begin{array}{l}1 \\
0.1\end{array}$ & $\begin{array}{r}107 \\
68\end{array}$ & $\begin{array}{l}78 \\
52\end{array}$ & $\begin{array}{l}51 \\
41\end{array}$ \\
\hline$d_{2}$ & $\begin{array}{l}1 \\
0.1\end{array}$ & $\begin{array}{r}113 \\
87\end{array}$ & $\begin{array}{r}106 \\
89\end{array}$ & $\begin{array}{r}101 \\
69\end{array}$ \\
\hline$d_{5}$ & $\begin{array}{l}1 \\
0.1\end{array}$ & $\begin{array}{r}113 \\
65\end{array}$ & $\begin{array}{r}125 \\
75\end{array}$ & $\begin{array}{r}107 \\
61\end{array}$ \\
\hline
\end{tabular}

B) Activities on rice seedling (Kotake-tamanishiki)

\begin{tabular}{cccc}
$\begin{array}{c}\text { Dosage } \\
\text { (ppm) }\end{array}$ & \multicolumn{4}{c}{$\begin{array}{c}\text { Length of 2nd leaf-sheath } \\
(\mathrm{mm})\end{array}$} \\
10 & $\mathrm{GA}_{3}$ & $\mathrm{GA}_{5}$ & $\mathrm{GA}_{20}$ \\
1 & - & 66 & 47 \\
0.1 & 63 & 39 & 26 \\
& 28 & 23 & 23
\end{tabular}

Control: $20 \mathrm{~mm}$

C) Activities on dwarf pea (Progress No. 9)

Dosage

( $\mu \mathrm{g} / \mathrm{plant})$

10
1

0.1

0.01

Control: $41 \mathrm{~mm}$

Growth promoting effects of $\mathrm{GA}_{20}$ on higher plants were compared with those of $\mathrm{GA}_{3}$ and $\mathrm{GA}_{5}$ using dwarf maize mutants $d_{1}, d_{2}, d_{5}$, rice seedlings and dwarf peas, according to the methods applied for $\mathrm{GA}_{19}$ (bamboo gibberellin). ${ }^{121}$ As shown in Table II, GA $\mathrm{A}_{5}$ and $\mathrm{GA}_{20}$ were highly active on dwarf maize $d_{2}$ and $d_{5}$

12) S. Tamura, N. Takahashi, N. Murofushi and J. Kato, Plant and Cell Physiol., 7, 677 (1966). 
but far less on $d_{1}$, rice seedlings and dwarf peas. Although both gibberellins showed similar action spectra, differences of activities between these higher plants were more enhanced in the case of $\mathrm{GA}_{20}$ than $\mathrm{GA}_{5}$. $\mathrm{GA}_{9}$ and $\mathrm{GA}_{19}$, which contain no hydroxyl group at $\mathrm{C}-2$, show similar activities to that of $\mathrm{GA}_{20}$ on these higher plants. This might be due to this structural feature.

\section{EXPERIMENTAL}

Thin layer chromatography. Throughout this study, thin layer chromatography was conducted under the following conditions unless otherwise stated: adsorbent, Silica gel $\mathrm{G}$ (Merck); solvent, benzene- $n$ butanol-acetic acid $(70: 25: 5, \mathrm{v} / \mathrm{v})$. Gibberellins on thin layer plates were detected by the treatment with $70 \%$ sulfuric acid followed by heating at $120^{\circ} \mathrm{C}$ for $10 \mathrm{~min}$ to develop fuorescent spots under ultra-violet light, and bioassays were adopted if necessary.

Gas chromatography. Retention times were determined with a Shimadzu GC-1B gas chromatograph fitted with a hydrogen flame-ionization detector. A silanized glass column, $1.5 \mathrm{~m} \times 4 \mathrm{~mm}$, was packed with $1.50^{\circ}$ SE-30 on Chromosorb W. Retention time of $\mathrm{GA}_{3}$ methyl ester was 9.1 min under the following conditions: carrier gas, nitrogen flowing at 57.5 $\mathrm{ml} / \mathrm{min}$; column temperature, $230^{\circ} \mathrm{C}$.

Determination of IR, NMR and mass spectroscopy. Infrared spectra were measured in nujol mulls with a JASCO IR-S KCl spectrometer. NMR spectra were determined with a JNM- $4 \mathrm{H}-100$ spectrometer with tetramethylsilane as the internal standard. Mass spectra were determined with CEC-110B and JMS-01S spectrographs equipped with direct inlet systems. The electron accelerating energy was $70 \mathrm{eV}$ and chamber temperature $150 \sim 180^{\circ} \mathrm{C}$.

Isolation of gibberellin $\mathbf{A}_{20}$. Immature seeds $(60 \mathrm{~kg})$ of morning-glory were extracted with methanol using a blender. The ethyl acetate-soluble acidic fraction was obtained from the methanol extract by the usual method. The acidic gum $(28.7 \mathrm{~g})$ thus obtained was purified in the following procedures.

A) Countercurrent distribution. The crude material was distributed between each $500 \mathrm{ml}$ of ethyl acetate and $1 \mathrm{M}$ phosphate buffer ( $\mathrm{pH}$ 5.5). After ten transfers countercurrent, first and eleventh fractions were excluded. Aqueous phases of fractions No. $2 \sim 10$ were combined, acidified to $\mathrm{pH} 3.0$ and ex- tracted with three $1500 \mathrm{ml}$ portions of ethyl acetate. The all ethyl acetate layers were combined and evaporated to afford $14.1 \mathrm{~g}$ of biologically active gum.

B) Charcoal column chromatography. The gum thus obtained was dissolved in water-acetone mixture $(80: 20, v / v)$, and charged on a column packed with $100 \mathrm{~g}$ of charcoal (Wako, activated charcoal for chromatography). The column was eluted with 1 liter of water-acetone $(80: 20, \mathrm{v} / \mathrm{v})$ and then acetone content was increased by $10 \%$ step for every 1 liter. Elution with acetone-water $(50: 50$ and $60: 40, \mathrm{v} / \mathrm{v})$ gave F-I $(1.8 \mathrm{~g})$ and acetone-water $(70: 30, \mathrm{v} / \mathrm{v})$ F-II $(1.5 \mathrm{~g})$.

C) Silicic acid adsorption chromatography. F-I and F-II were purified by different columns of silicic acid $(30 \mathrm{~g})$. Each column was eluted with $100 \mathrm{ml}$ portions of benzene-ethyl acetate mixture increasing ethyl acetate content. The most active fraction $(62$ $\mathrm{mg}$ ) was obtained from F-I by the elution with benzene-ethyl acetate $(45: 55$ and $40: 60, \mathrm{v} / \mathrm{v})$ and that $(110 \mathrm{mg})$ from F-II with benzene-ethyl acetate (65:35 55:45, v/v).

D) Preparative thin layer chromatography. Each active fraction obtained from F-I and F-II was spotted on thin layer of silica gel $(0.5 \mathrm{~mm}$ in thickness). After development with benzen- $n$-butanol-acetic acid $(70: 25: 5, \mathrm{v} / \mathrm{v})$, the active zones $(R f 0.42$ in F-I and $R f 0.67$ in F-11) were cut off and extracted with ethyl acetate to afford active gum, which was treated with diazomethane. The methyl ester obtained from F-I was subjected to thin layer chromatography as well as gas chromatography and identified as $\mathrm{GA}_{3}$ methyl ester. The ester from F-II was further purified with preparative thin layer chromatography by the use of ethyl ether-benzene $(4: 1, v / v)$. The zone corresponding to $R f 0.4$ was extracted with ethyl acetate to afford $11 \mathrm{mg}$ of rods, which were then recrystallized from acetone- $n$-hexane to give $7 \mathrm{mg}$ of pure $\mathrm{GA}_{20}$ methyl ester, $\mathrm{mp} 181^{\circ} \mathrm{C}$. Found: mol. wt. 346.177 (MS). Calcd. for $\mathrm{C}_{20} \mathrm{H}_{26} \mathrm{O}_{5}$ : mol. wt. 346.178. $I_{\max }^{\mathrm{Nujoi}} \mathrm{cm}^{-1}: 3520,1778,1720,1670,882$. NMR (in $\left.\mathrm{CDCl}_{3}\right) \tau: 8.90(3 \mathrm{H}, \mathrm{s}), 6.33(3 \mathrm{H}, \mathrm{s}), 5.10$ $(1 \mathrm{H}, \mathrm{s}), 4.80(1 \mathrm{H}, \mathrm{s})$.

Hydrolysis of $\mathbf{G A}_{20}$ methyl ester. To a solution of $5 \mathrm{mg}$ of $\mathrm{GA}_{20}$ methyl ester in $0.3 \mathrm{ml}$ of ethanol, was added $3 \mathrm{ml}$ of $0.1 \mathrm{~N}$ aqueous sodium hydroxide solution. On standing at $30^{\circ} \mathrm{C}$ for $20 \mathrm{hr}$, the solution was neutralized to $\mathrm{pH} 7$ with dil. $\mathrm{H}_{2} \mathrm{SO}_{4}$ and concentrated. The aqueous residue was extracted with ethyl acetate to give acidic and neutral frac- 
tions according to the usual method. On evaporation of the solvent, the acidic fraction gave $3 \mathrm{mg}$ of crude crystals, which were then recrystallized from acetone- $n$-hexane to afford $2 \mathrm{mg}$ of $\mathrm{GA}_{20}$ as rods melting at $232 \sim 233^{\circ} \mathrm{C}$. IR ${ }_{\max }^{\mathrm{Nujol}} \mathrm{cm}^{-1}: \quad 3420,1767$, 1738, 1664, 878. $\mathrm{GA}_{20}$ thus obtained regenerated $\mathrm{GA}_{20}$ methyl ester on treatment with diazomethane.

Preparation of $\mathbf{G A}_{20}$ methyl ester from $\mathbf{G A}_{5}$ methyl ester. $\mathrm{GA}_{5}$ methyl ester (148 mg) was hydrogenated over $2 \%$ palladium on barium carbonate $(300 \mathrm{mg})$ in ethyl acetate $(18 \mathrm{ml})$ and pyridine $(1.2 \mathrm{ml})$ under atmospheric pressure until one molar equivalent hydrogen $\left(10.5 \mathrm{ml}\right.$, at $\left.20^{\circ} \mathrm{G}\right)$ was absorbed. After removal of the catalyst the solvent was evaporated and the residue was charged into a column of silicic acid $(40 \mathrm{~g}$, impregnated with $10 \mathrm{~g}$ of silver nitrate). The column was successively eluted with $500 \mathrm{ml}$ of benzene-ethyl acetate $(95: 5, \mathrm{v} / \mathrm{v}$, fractions No. $1 \sim 30$ ) and $500 \mathrm{ml}$ of the same solvent system with a varied composition $(92: 8, \mathrm{v} / \mathrm{v}$, fractions No. $31 \sim 60)$. The components in each fraction were examined by thin layer chromatography using silicic acid impregnated with silver nitrate and NMR spectra. Fractions No. $6 \sim 20$ were found to contain IV and V, fractions No. $21 \sim 24$ II, fractions No. $25 \sim 35$ II and III, and fractions No. $36 \sim 47$ III.
Then fractions No. $2 \mathrm{I} \sim 24$ were combined and evaporated to afford $22 \mathrm{mg}$ of crystals. Recrystallization from acetone- $n$-hexane yielded $20 \mathrm{mg}$ of rods melting at $183^{\circ} \mathrm{C}$. Its IR and NMR spectra were completely identical with those of $\mathrm{GA}_{20}$ methyl ester obtained from immature seeds of morning-glory.

Acknow ledgements. The authors wish to express their thanks to Dr. Y. Sumiki, Emeritus Professor of The University of Tokyo, for his encouragement through this work. They are grateful to Sankyo Co. for supplying them with immature seeds of morning-glory, to Kaken Chemical Co. for the help in extraction of crude materials, and to Prof. B. O. Phinney, University of California, Los Angeles, for the supply of dwarf maize seeds. They are also indebted to Drs. T. Tsuchiya, N. Waseda and H. Hoshino, Government Chemical Industrial Research Institute, Tokyo, and members of Japan Electron Optics Laboratory for the measurement of high resolution mass spectra and Mr. K. Aizawa of this Department for the measurement of IR and NMR spectra. 